\title{
Less Blood Loss With Tranexamic Acid in Primary Total Hip Arthroplasty Using the Direct Anterior Approach: a One-center Retrospective Observational Study
}

\author{
Xian-Ren Zhu \\ Department of Orthopedic Surgery, the Affiliated Hospital of Xuzhou Medical University \\ Lei Wang \\ Department of Orthopedics, the First Affiliated Hospital of Wannan Medical College \\ Hong-Wei Li \\ Department of Orthopedic Surgery, the Affiliated Hospital of Xuzhou Medical University \\ Guo-Chun Zha (D 41049015@qq.com) \\ Department of Orthopedic Surgery, the Affiliated Hospital of Xuzhou Medical University
}

\section{Research Article}

Keywords: total hip arthroplasty, tranexamic acid, blood loss, direct anterior approach

Posted Date: July 21 st, 2021

DOI: https://doi.org/10.21203/rs.3.rs-725510/v1

License: (c) (i) This work is licensed under a Creative Commons Attribution 4.0 International License.

Read Full License 


\section{Abstract}

Background: It is still not known whether tranexamic acid is beneficial for the minimally invasive surgical approach to total hip arthroplasty (THA). This study seeks to investigate the efficacy and safety of intravenous tranexamic acid (TXA) in primary THA via the direct anterior approach (DAA).

Methods: We performed a retrospective analysis of prospectively collected data on 70 patients with nontraumatic avascular necrosis of the femoral head who underwent total hip arthroplasty (THA) via the DAA between October 2017 and October 2018. Patients were divided into two groups: TXA group (39 patients who did receive 1.5g TXA intravenously) and control group (31 patients who did not receive TXA). Patients were assessed by the operative time, postoperative hemoglobin (HB) drop, transfusion rate, postoperative length of hospital stays (LHS), deep vein thrombosis (DVT), and Harris hip score (HHS).

Results: The total blood loss, hidden blood loss, and postoperative HB drop in the TXA group were significantly lower than those in the control group $(p<0.05)$. There was no statistical difference in terms of intraoperative blood loss, operation time, transfusion rate, postoperative LHS, HHS, and the incidence of DVT between the two groups ( $p>0.05)$.

Conclusion: TXA may be reduce perioperative blood loss and not increase complications, in THA via the DAA.

\section{Introduction}

Total hip arthroplasty (THA) has been widely used for the treatment of end-stage hip disease, and it can effectively relieve pain, restore function and improve the quality of life [1]. It has been reported that the total blood loss can be as high as $2000 \mathrm{~mL}$, and the transfusion rate was as high as $37 \%$ during perioperative period of THA [2-4]. Massive blood transfusion not only increases the risk of surgery, but also causes the spread of viral diseases, hemolytic reactions, immunologic reactions and other transfusion-related risks $[5,6]$.

With the popularization of minimally invasive concept and the continuous improvement of prosthesis materials and design, there are a variety of THA surgical approaches available clinically, such as direct anterior approach (DAA), anterolateral approach, posterior approach, posterolateral approach, SuperPATH approach, lateral approach. Among them, the DAA is a minimally invasive surgical approach through the intermuscular space and nerve gap. This approach has the advantages of minimizing soft tissue disruption and reducing the incidence of dislocation [7-9]. As a synthetic antifibrinolytic agent, TXA has been shown to be effective in reducing blood loss and transfusion rate in THA [10,11]. However, few studies have explored the efficacy of TXA on perioperative blood loss in primary THA using the DAA [12, 13] - in other words, it is still not known whether tranexamic acid is beneficial for the minimally invasive surgical approach to THA.

Therefore, this study aimed to investigate the efficacy and safety of intravenous TXA in THA via the DAA. 


\section{Materials And Methods \\ 2.1. Patients}

We performed a retrospective analysis of prospectively collected data on 70 patients (70 hips) with nontraumatic avascular necrosis of the femoral head who underwent total hip arthroplasty (THA) via the direct anterior approach (DAA) between October 2017 and October 2018. Patients were divided into two groups: TXA group (39 patients who did receive 1.5g TXA intravenously) and control group (31 patients who did not receive TXA). The Medical Ethics Committee of the Affiliated Hospital of Xuzhou Medical University approved the study protocol according to the declaration of Helsinki and all study participants gave their written informed consent.

\subsection{Study setting}

All surgeries were performed by the senior author (Z.G.C) using cementless THA via DAA. All patients received a general anesthetic and received a same design of the femoral stem (CLS stem; Zimmer, Warsaw, USA) and cup (Trilogy; Zimmer, Warsaw, USA). We did not use a wound drain following surgery. In the TXA group, TXA was given as a $1.5 \mathrm{~g}$ intravenous infusion 10 minutes prior to incision; the control group did not receive TXA.

All Patients were managed with a similar perioperative regimen, including intravenous prophylactic antibiotics, prophylaxis against venous thrombosis and post-operative pain control.

Patients were transfused if postoperative hemoglobin level was less than $70 \mathrm{~g} / \mathrm{L}$ or when the hemoglobin of a patient was more than $70 \mathrm{~g} / \mathrm{L}$ and less than $100 \mathrm{~g} / \mathrm{L}$ but with a bad mental status, palpitation or pallor. All patients underwent deep vein ultrasound of the lower limbs 1 week postoperatively to detect thrombosis.

\subsection{Data collection}

Data were collected on patient characteristics including gender, age, body mass index (BMI), preoperative hemoglobin (HB), preoperative HCT, and American Society of Anesthesiologists (ASA) classification. HB and HCT levels were also measured at each time point post-operative days one and three. The operative time, transfusion rate, postoperative HB drop, postoperative length of hospital stays (LHS), and Harris hip score (HHS) were recorded. The total blood loss and pulmonary blood volume (PBV) were calculated according to the Gross and Nadler equation $[14,15]$.

$\mathrm{PBV}=\mathrm{K} 1 \times$ height3 (meters) $+\mathrm{K} 2 \times$ weight (kilograms) $+\mathrm{k} 3 . \mathrm{k} 1=0.3669, \mathrm{~K} 2=0.03219$, and $\mathrm{k} 3=0.6041$ for men; and $\mathrm{k} 1=0.3561, \mathrm{~K} 2=0.03308$, and $\mathrm{k} 3=0.1833$ for women.

The total red blood cell volume loss $=$ PBV $\times($ Hctpre - Hctpost $)$, Hctpre $=$ the initial preoperative Hct level, Hctpost $=$ the Hct of the third postoperative day.

The total blood loss $=1000 \times$ the total red blood cell volume loss $/$ (the average of the Hctpre and Hctpost). 
The postoperative HB drop $=\mathrm{HBpre}-\mathrm{HBpost}, \mathrm{HBpre}=$ the initial preoperative $\mathrm{HB}$ level, $\mathrm{HBpost}=$ the $\mathrm{HB}$ of the third postoperative day.

The obvious blood loss $=$ Intraoperative blood loss + postoperative blood loss .

The hidden blood loss $=$ the total blood loss-obvious blood loss.

\subsection{Statistical methods}

All the statistical analyses were performed using SPSS version 19.0 (SPSS Inc. USA). Means are presented as mean $\pm S D$, Student-t test was used to analyze the normal distributed numerical variable; Pearson chi-square test or Fisher exact test was used to analyze the qualitative variable. The significance level used for all tests was $p<0.05$.

\section{Results}

\subsection{Patient characteristics}

All patients were followed for three months. Detailed distribution of patient demographics and characteristics was shown in Table 1.

Table 1

Demographics of both groups

\begin{tabular}{|llll|}
\hline Variable & TXA group $(\mathbf{n}=39)$ & Control group $(\mathbf{n}=31)$ & $\mathrm{p}$-value \\
\hline Mean age (years) & $54.4 \pm 13.6(24-83)$ & $53.7 \pm 15.4(25-83)$ & 0.841 \\
\hline Sex ratio (male: female) & $26: 13$ & $20: 11$ & 0.851 \\
\hline Mean BMI (kg/m $\left.{ }^{2}\right)$ & $22.3 \pm 2.6(17.8-25.5)$ & $22.2 \pm 2.8(17.9-28.5)$ & 0.878 \\
\hline ASA classification(l:Il) & $33: 6$ & $27: 4$ & 0.768 \\
\hline Follow-up (months) & 3 & 3 & - \\
\hline
\end{tabular}

\subsection{Operative variable}

The operative time, intraoperative blood loss, hidden blood loss, total blood loss, preoperative HB level, HB level of the first postoperative day, HB level of the third postoperative day, postoperative HB drop, and transfusion rate was shown in Table 2. In the TXA group, 2.6\% (1/39) required blood transfusion with 2unit $(400 \mathrm{~mL})$ red blood cells suspension (RBCs), whereas in the control group, $12.9 \%(4 / 31)$ required blood transfusion with 8-unit (1600 mL) RBCs (2 units per patient). The total blood loss, hidden blood loss, and postoperative HB drop in the TXA group were significantly lower than those in the control group $(p<0.05)$. There was no statistical difference in terms of the operative time, intraoperative blood loss, and transfusion rate between the two groups ( $p>0.05)$. 
Table 2

Clinical outcomes of both groups

\begin{tabular}{|c|c|c|c|}
\hline Variable & TXA group $(n=39)$ & Control group $(n=31)$ & p-value \\
\hline Operative time (min) & $57.4 \pm 12.8(43-109)$ & $60.4 \pm 11.7(42-89)$ & 0.315 \\
\hline Intraoperative blood loss (mL) & $106.5 \pm 36.1(78-200)$ & $122.0 \pm 32.6(75-207)$ & 0.067 \\
\hline The hidden blood loss (mL) & $630.5 \pm 98.6(409-807)$ & $893.4 \pm 140.3(644-1175)$ & 0.000 \\
\hline The total blood loss (mL) & $736.9 \pm 102.2(567-927)$ & $1015.4 \pm 152.4(773-1285)$ & 0.000 \\
\hline HBpre* $^{\star}(\mathrm{g} / \mathrm{L})$ & $134.2 \pm 12.0(114-159)$ & $134.8 \pm 10.1(113-155)$ & 0.825 \\
\hline $\mathrm{HB}_{\text {post }-1}{ }^{*}(\mathrm{~g} / \mathrm{L})$ & $108.9 \pm 14.9(85-140)$ & $99.2 \pm 13.8(80-132)$ & 0.007 \\
\hline $\mathrm{HB}_{\text {post }-3}{ }^{*}(\mathrm{~g} / \mathrm{L})$ & $87.4 \pm 16.3(63-128)$ & $79.8 \pm 10.9(56-110)$ & 0.029 \\
\hline Postoperative HB drop ( $\mathrm{g} / \mathrm{L})$ & $46.8 \pm 10.8(22-80)$ & $55.0 \pm 13.7(31-79)$ & 0.007 \\
\hline Transfusion rate (\%) & $2.6 \%(1 / 39)$ & $12.9 \%(4 / 31)$ & 0.163 \\
\hline Postoperative LHS (day) & $4.3 \pm 0.8(3-6)$ & $4.6 \pm 0.8(3-6)$ & 0.124 \\
\hline DVT (\%) & $2.6 \%(1 / 39)$ & $3.2 \%(1 / 31)$ & 1.000 \\
\hline Harris hip score (point) & $91.8 \pm 4.9(80-100)$ & $91.1 \pm 6.1(83-100)$ & 0.596 \\
\hline
\end{tabular}

\subsection{Clinical results and complications}

All patients were successfully completed the operation. All patients did not receive blood transfusion on the third postoperative day. There was no statistical difference in terms of postoperative LHS, HHS, and the incidence of DVT between the two groups $(p>0.05)$ (Table 2).

Two patients (1 patient per group) sustained intraoperative fractures of the calcar during seating of the stem, and the fractures were treated by cerclage wire fixation. Subsidence of the stem during loading was not observed after three months of follow-up. There were two patients (1 patient per group) with asymptomatic DVT who did not receive any special treatment. No incision infection occurred in the two groups. No patient died during the study period.

\section{Discussion}

TXA is a synthetic derivative of the amino acid lysine, which can reduce fibrinolysis through the reversible blockade of lysine binding sites on plasminogen molecules [16]. More and more evidences show that TXA can effectively reduce perioperative blood loss and transfusion rate in THA. Most studies have been 
performed on the posterolateral approach $[11,17]$ or the lateral approach $[18]$ or the posterior approach $[19,20]$ in THA. However, there is less research on TXA in the DAA for THA $[12,13]$. This study aimed to explore whether TXA reduced perioperative blood loss and the rate of blood transfusion in patients undergoing THA via the DAA.

In the present study, the intravenous infusion of $1.5 \mathrm{~g}$ of TXA which was effective in reducing total blood loss, hidden blood loss, and the degree of $\mathrm{Hb}$ drop, but did not significantly intraoperative blood loss and transfusion rate during perioperative period in DAA THA. Fraval et al. [12] performed a single-center randomized, double-blind trial in which 101 patients underwent THA via DAA, and 50 of them received TXA during the perioperative period. It was found that TXA could significantly reduce the blood loss (including intraoperative blood loss and calculated blood loss), but there was no statistical significance in transfusion rate between the both groups. Our results are consistent with Fraval et al. [12], except for the intraoperative blood loss. We speculate that the reason is that these patients in our study have a younger age, lower of BMI and shorter of operative time than those in Fraval et al. [12] study. In addition, our results are not exactly the same as Free et al. [13] study, they found that the transfusion rate after TXA was $1.2 \%$ in THA using DAA, which was significantly lower than the transfusion rate of $11.1 \%$ in the control group. We speculate that the reason is that these patients in our study have a younger age, lower of BMI and lower of ASA score than those in Free et al. [13] study. Whether TXA can reduce the transfusion rate for THA via DAA requires more sample size and more prospective studies to determine.

Several studies $[12,23]$ have found that the use of TXA can reduce the LHS during the perioperative period of THA. However, our study found that the use of TXA during perioperative period of THA via DAA did not shorten the postoperative LHS. We speculate that the reason is that DAA is a minimally invasive procedure that can shorten the LHS. Whether TXA can reduce the LHS for THA via DAA requires more sample size and more prospective studies to determine.

Many literatures $[11,24,25]$ have reported that the use of TXA did not increase the incidence of DVT in patients undergoing THA. However, Nishihara et al. [26] conducted a study to observe whether TXA increased the risk of DVT in lower limbs without routine chemical thromboprophylaxis, and finally found that the use of TXA would increase in the incidence of distal DVTs in the muscular veins. Our study found that 1 case of DVT occurred in the TXA group, and 1 case in the control group, the difference was not statistically significant $(p=1.000)$. Perioperative use of TXA during THA via DAA did not increase the incidence DVT in the lower extremities.

In this study, there are several limitations. The incidence of DVT in the lower extremities was assessed only in the short term. Our sample size is small and the results may be biased. A larger randomized prospective trial is required to further improve the relevant experiments to determine the efficacy and safety of TXA in the perioperative period of THA via DAA.

\section{Conclusion}


Single administration of $1.5 \mathrm{~g}$ intravenous infusion 10 minutes prior to incision, may be effectively reduce the perioperative blood loss in primary THA through DAA, and may be not increase the incidence of DVT of lower extremities.

\section{Abbreviations}

$T X A=$ Tranexamic acid, $T H A=$ Total hip arthroplasty, DAA= Direct anterior approach, $\mathrm{HB}=$ Hematoglobin, DVT = Deep vein thrombosis, LHS= Length of hospital stays, $\mathrm{HHS}=$ Harris hip score, BMI=Body mass index, HCT= Hematocrit, ASA=American Society of Anesthesiologists, PBV= Pulmonary blood volume

\section{Declarations}

\section{Acknowledgements}

The authors thank Shuo Feng and Zhi Yang from the Department of Orthopedic Surgery, Affiliated Hospital of Xuzhou Medical University for the Working Environment for valuable technical assistance and support.

\section{Funding}

This work was supported by the Jiangsu Provincial Medical Youth Talent (QNRC2016800), the Foundation of Jiangsu Province commission of Health and Family Planning (H2017081) and the Special Scientific Research Fund for Introducing Talents in Yijishan Hospital. No benefits in any form have been received or will be received from a commercial party related directly or indirectly to the subject of this article. These funding were used in the design of the study and collection, analysis, and interpretation of data and in writing the manuscript.

\section{Availability of data and materials}

All data generated or analyzed during this study are included in this published article, and the supplementary file. We do not wish to share our patients' data because it involves patient's privacy.

\section{Authors' contributions}

GCZ designed the study, performed the surgery, acquired, analyzed and interpreted the data, drafted and revised the manuscript. XRZ acquired, analyzed, and interpreted the data, drafted and revised the manuscript. LW and HWL analyzed and interpreted the data, Revised the manuscript.

\section{Competing interests}

The authors declare that they have no competing interests.

\section{Ethics approval and consent to participate}


This study has been approved by the Ethic Committee of the Affiliated Hospital of Xuzhou Medical University (NO.20171012). The written consent was obtained from all participants in the study.

\section{References}

1. O'boyle C A, Mcgee H, Hickey A, O'malley K, Joyce C R. Individual quality of life in patients undergoing hip replacement[J]. Lancet, 1992, 339(8801): 1088-91.

2. Bierbaum B E, Callaghan J J, Galante J O, Rubash H E, Tooms R E, Welch R B. An analysis of blood management in patients having a total hip or knee arthroplasty[J]. J Bone Joint Surg Am, 1999, 81(1): 2-10.

3. Rosencher N, Kerkkamp H E, Macheras G, Munuera L M, Menichella G, Barton D M, et al. Orthopedic Surgery Transfusion Hemoglobin European Overview (OSTHEO) study: blood management in elect ive knee and hip arthroplasty in Europe[J]. Transfusion, 2003, 43(4): 459-69.

4. Young S W, Marsh D J, Akhavani M A, Walker C G, Skinner J A. Attitudes to blood transfusion post arthroplasty surgery in the United Kingdom: a national survey[J]. Int Orthop, 2008, 32(3): 325-9.

5. Busch M P, Kleinman S H, Nemo G J. Current and emerging infectious risks of blood transfusions[J]. Jama, 2003, 289(8): 959-62.

6. Vamvakas E C, Blajchman M A. Transfusion-related mortality: the ongoing risks of allogeneic blood transfusion and the available st rategies for their prevention[J]. Blood, 2009, 113(15): 3406-17.

7. Kennon R E, Keggi J M, Wetmore R S, Zatorski L E, Huo M H, Keggi K J. Total hip arthroplasty through a minimally invasive anterior surgical approach[J]. J Bone Joint Surg Am, 2003, 85-A Suppl 4: 39-48.

8. Berger R A, Jacobs J J, Meneghini R M, Della Valle C, Paprosky W, Rosenberg A G. Rapid rehabilitation and recovery with minimally invasive total hip arthroplasty[J]. Clin Orthop Relat Res, 2004, (429): 239-47.

9. Bremer A K, Kalberer F, Pfirrmann C W, Dora C. Soft-tissue changes in hip abductor muscles and tendons after total hip replacement: comparison betwe en the direct anterior and the transgluteal approaches[J]. J Bone Joint Surg Br, 2011, 93(7): 886-9.

10. Othman Y, Melebeck F, Daubresse F. Tranexamic acid in joint replacement: a randomized trial comparing intravenous oral and topical routes[J]. Acta Orthop Belg, 2020, 86(3):397-404.

11. Yi Z, Bin S, Jing Y, Zongke Z, Pengde K, Fuxing P. Tranexamic Acid Administration in Primary Total Hip Arthroplasty: A Randomized Controlled Trial of In travenous Combined with Topical Versus Single-Dose Intravenous Administration[J]. J Bone Joint Surg Am, 2016, 98(12): 983-91.

12. Fraval A, Effeney P, Fiddelaers L, Smith B, Towell B, Tran P. OBTAIN A: Outcome Benefits of Tranexamic Acid in Hip Arthroplasty. A?Randomized Double-Blinded Contro lled Trial[J]. J Arthroplasty, 2017, 32(5): 1516-19.

13. Free M D, Owen D H, Pascoe E, Allen P, Yang L, Harvie P. Transfusion rates with intravenous tranexamic acid in total hip arthroplasty performed using the dire ct anterior approach[J]. Hip Int, 2018: 1120700018811310. 
14. Nadler S B, Hidalgo $\mathrm{J} \mathrm{H}$, Bloch T. Prediction of blood volume in normal human adults[J]. Surgery, 1962, 51(2): 224-32.

15. Gross J B. Estimating allowable blood loss: corrected for dilution[J]. Anesthesiology, 1983, 58(3): 277-80.

16. Dunn C J, Goa K L. Tranexamic acid: a review of its use in surgery and other indications[J]. Drugs, 1999, 57(6): 1005-32.

17. Yamasaki S, Masuhara K, Fuji T. Tranexamic acid reduces blood loss after cementless total hip arthroplasty-prospective randomized stu dy in 40 cases[J]. Int Orthop, 2004, 28(2): 69-73.

18. Benoni G, Fredin H, Knebel R, Nilsson P. Blood conservation with tranexamic acid in total hip arthroplasty: a randomized, double-blind study i n 40 primary operations[J]. Acta Orthop Scand, 2001, 72(5): 442-8.

19. Kayupov E, Fillingham Y A, Okroj K, Plummer D R, Moric M, Gerlinger T L, et al. Oral and Intravenous Tranexamic Acid Are Equivalent at Reducing Blood Loss Following Total Hip Arthro plasty: A Randomized Controlled Trial[J]. J Bone Joint Surg Am, 2017, 99(5): 373-78.

20. Lee Q J, Chang W Y, Wong Y C. Blood-Sparing Efficacy of Oral Tranexamic Acid in Primary Total Hip Arthroplasty[J]. J Arthroplasty, 2017, 32(1): 139-42.

21. Husted H, Blønd L, Sonne-Holm S, Holm G, Jacobsen T W, Gebuhr P. Tranexamic acid reduces blood loss and blood transfusions in primary total hip arthroplasty: a prospe ctive randomized double-blind study in 40 patients[J]. Acta Orthop Scand, 2003, 74(6): 665-9.

22. Rajesparan K, Biant L C, Ahmad M, Field R E. The effect of an intravenous bolus of tranexamic acid on blood loss in total hip replacement[J]. J Bone Joint Surg Br, 2009, 91(6): 776-83.

23. Konig G, Hamlin B R, Waters $\mathrm{J} \mathrm{H}$. Topical tranexamic acid reduces blood loss and transfusion rates in total hip and total knee arthropl asty[J]. J Arthroplasty, 2013, 28(9): 1473-6.

24. Alshryda S, Mason J, Sarda P, Nargol A, Cooke N, Ahmad H, et al. Topical (intra-articular) tranexamic acid reduces blood loss and transfusion rates following total hi $p$ replacement: a randomized controlled trial (TRANX-H) [J]. J Bone Joint Surg Am, 2013, 95(21): 1969-74.

25. El Beheiry H, Lubberdink A, Clements N, Dihllon K, Sharma V. Tranexamic acid administration to older patients undergoing primary total hip arthroplasty conserves hemoglobin and reduces blood loss[J]. Can J Surg, 2018, 61(3): 177-84.

26. Nishihara S, Hamada M. Does tranexamic acid alter the risk of thromboembolism after total hip arthroplasty in the absence of routine chemical thromboprophylaxis? [J]. Bone Joint J, 2015, 97-b (4): 458-62. 